\title{
Mobile Tower Radiation and Its Impacts on Child Health: a Study Conducted in an Ecologically Sensitive Area of Western Ghats
}

Premlal P. D., Eldhose N. V.

Department of Electronics, STAS, Mahatma Gandhi University Regional Centre, India

\begin{tabular}{l}
\hline \hline Article Info \\
\hline Article history: \\
Received Sep 28, 2017 \\
Revised May 30, 2018 \\
Accepted Jun 13, 2018 \\
\hline Keyword: \\
Cell tower radiation \\
Child health \\
Power density \\
Radiation level \\
RF exposure
\end{tabular}

\begin{abstract}
The effect of mobile tower radiation on child health in an ecologically sensitive area of Western Ghats in Idukki, Kerala is studied. In this paper, we have attempted to discover whether any relation exists between the RF exposure and the health of children under 15 years old. At some point of path of this work, twenty common diseases were considered. From our analysis, it has been discovered that five of them are very much related to RF exposure. Furthermore, the age group between ten to fifteen years is more vulnerable to mobile tower radiation, and boys are observed to be more affected than girls. In the region under study, exposure levels were well below the ICNIRP recommendations and the current Indian standards. However, still it is inadequate to safeguard children. So it is recommended to modify the current Indian standard of RF exposure.
\end{abstract}

Copyright $(0) 2018$ Institute of Advanced Engineering and Science. All rights reserved.

\section{Corresponding Author:}

Premlal P. D.,

Department of Electronics, School of Technology and Applied Sciences,

Mahatma Gandhi University Regional Centre,

Edappally, Kochi-24, Kerala, India.

Email: premlalpd@gmail.com

\section{INTRODUCTION}

With boom in cell phone communication the number of cell phone towers getting installed is increasing day by day all over the world. People have been debating the ill effects of radiation on human, birds and animals [1]-[5]. The effects can be classified as short term thermal effects and long term nonthermal effects [6]. Thermal effects are similar to that of principle used in microwave oven. But non-thermal effects are not well defined. Several studies [7]-[9] reported that non-thermal effects are more harmful than thermal effects. Unfortunately no universal standard exists to propose a more secure restrict [6].

Since human body consists of more than $70 \%$ of liquid, the comparison with microwave oven is relevant. When the body is exposed to radiation, it absorbs a part of the RF energy, which will heat up the body $[6,10]$. The effect is more on the parts of the body which contain more liquid, and where the flow is less like eyes, brain, joints, heart, abdomen, etc. [6]. Multiple resonances will take place in the body, since the wave lengths of mobile tower radiations are compatible with the lengths of different parts of the body. This will generate more heat and boil the water contents of these body parts and as a result the functions of like eyes, ears, joints, bones, brain, abdomen etc may affected. Long term RF exposure will create severe problems. Unfortunately, common people are not much aware of these problems. Severel researchers across the world are already reported the harmful effects of RF radiations on human body [7], [8] India has been adopting a radiation norm of $470 \mathrm{~mW} / \mathrm{m}^{2}$ for power density, which is $1 / 10$ th of the recommendation by ICNIRP. However, this is applicable for a single carrier frequency. But in India, towers contain multiple carriers and multiple operators. This will cumulate the RF exposure effects. Studies across the world already shown the inadequacies of the ICNIRP standards [13]-[16]. 
Children are found to be more affected by the RF exposure [17], [18]. This is because of their smaller head, thinner bones, tender skin, elastic ears, more reproducing cells etc. So the radiation penetrates more than the adults. Our aim is to analyse the above facts which will enable us to get a clear picture about the mobile tower radiation exposure and the health troubles of the children. Our observation location includes the ecologically sensitive areas of the Western Ghats. An environmental research commission was appointed by the Government of India known as Western Ghats Ecology Expert Panel (WGEEP) or Gadgil Commission. About $67 \%$ of the place underneath the Western Ghats was found to be ecologically sensitive, and construction works in the respective region were prohibited [19]. More than 2000 mobile towers are already installed in the above notified region in Idukki district of Kerala state. Our study confirms the effects of RF exposure on five out of the twenty major diseases among children in the notified area. Section 2 of this paper discusses the methodology adopted in this work. Section 3 explains the results and finally section 4 concludes the study.

\section{METHODOLOGY}

The geographical location of our study consists of four villages of Udumpumchola taluk in Idukki. This belongs to the ecologically sensitive zone as per the Gadgil Commission report [19]. Our primary intention is to study whether or not any relation exists between the cell tower radiation and the health of children. We divided the examination area into two; Highly Exposed Zone (HEZ), which is the area within a radius of 300 metres of any cell tower and Radiation Free Zone (RFZ) at a distance more than 300 metres from any cell tower. Power density, electric field intensity and magnetic field intensities were measured and a survey was conducted in more than 60 houses to find out the effects of children's health. Statistical tests have been conducted to conclude the assessments. The device used for measuring the exposure parameters was MECO's 9720 three axes radiation metre.

\section{RESULTS AND DISCUSSION}

Twenty diseases were examined to discover if any relation exists between any one of them and the RF exposure levels. Our observation is that five of them definitely have some connection with the mobile tower exposure.

\subsection{Bone Weakness}

It is found that $18 \%$ of the children in our survey were found to be affected by bone weakens. The age wise comparison is shown in the Figure 1. From Figure 1 it is clear that the age group 10-15 is more affected. In gender wise analysis, $70 \%$ of the sufferers are boys and $30 \%$ are from girls category. In zone wise analysis, it has been found that approximately $90 \%$ of the victims are from HEZ and only about $10 \%$ are from RFZ. Our conclusion is that the $80 \%$ hike found in the HEZ is because of the mobile tower radiation.

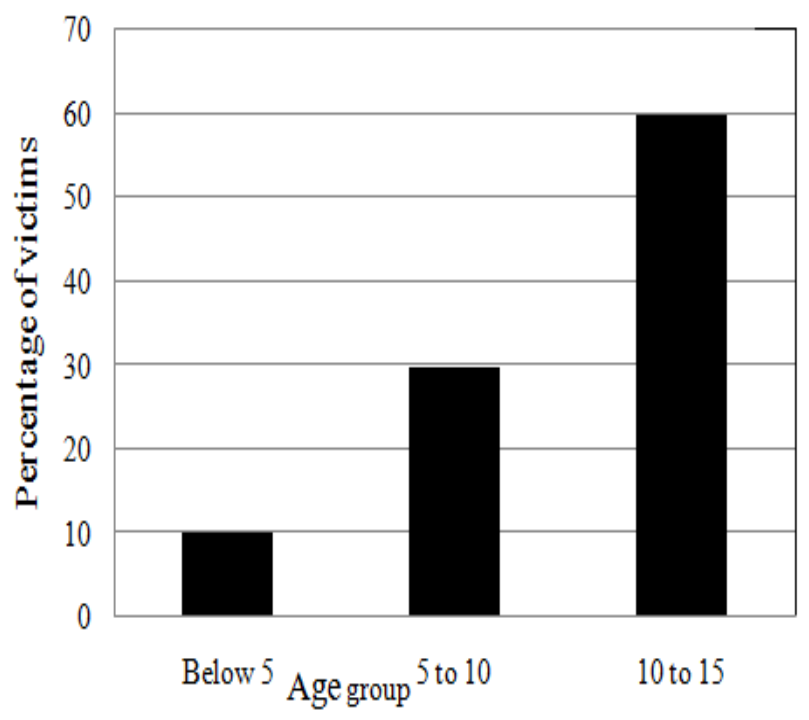

Figure 1. Age group comparison-bone weakness 


\subsection{Headaches}

$26 \%$ of the children in our survey are found to be suffering from frequent headaches. The result of age wise comparison is as shown in the Figure 2. Here also the age group from 10 to 15 is more affected. In a gender wise analysis, girls are found to be the major victims of headaches (57.14\%) whereas boys constitute only $42.86 \%$. In the case of headaches, $85.71 \%$ of the affected are from HEZ and only $14.29 \%$ are from RFZ. It is evident that the $71.42 \%$ increase in headaches is caused by exposure to cell tower radiations.

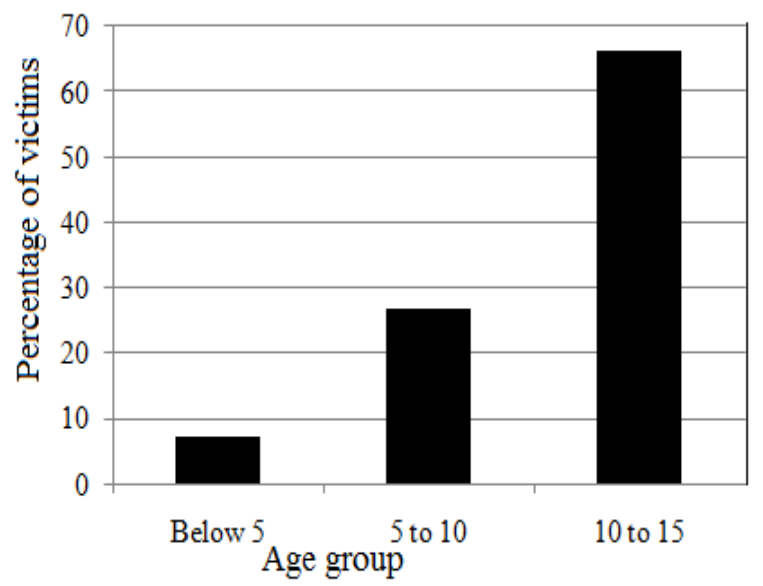

Figure 2. Age group comparison-headaches

\subsection{Rheumatic Pain}

Approximately $12 \%$ of the children under our study are affected by rheumatic related join pain. The age wise comparison is as shown in Figure 3. The 10-15 age group is the major victim of rheumatic pain. In a gender wise analysis, boys are found to be the most affected (78.81\%), while only $14.29 \%$ of girls are affected. Exposure wise comparison shows that $85.71 \%$ is from HEZ and only $14.29 \%$ from RFZ. Here also cell tower exposure is the major cause.

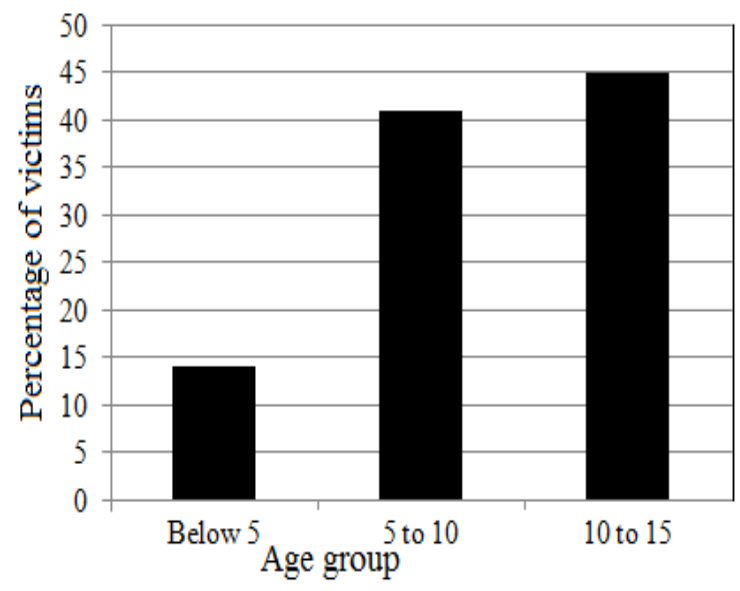

Figure 3. Age group comparison-rheumatic pain

\subsection{Sleep Disorders}

About $22 \%$ of the children are found to be tormented by sleep disorders. The Figure 4 shows the age wise comparison. About $58.33 \%$ of the victims are boys and $41.67 \%$ are girls. In zone wise comparison, $83.33 \%$ are from HEZ and only $16.17 \%$ from RFZ. This definitely shows that the variable which causes the distinction is nothing but RF exposure. 


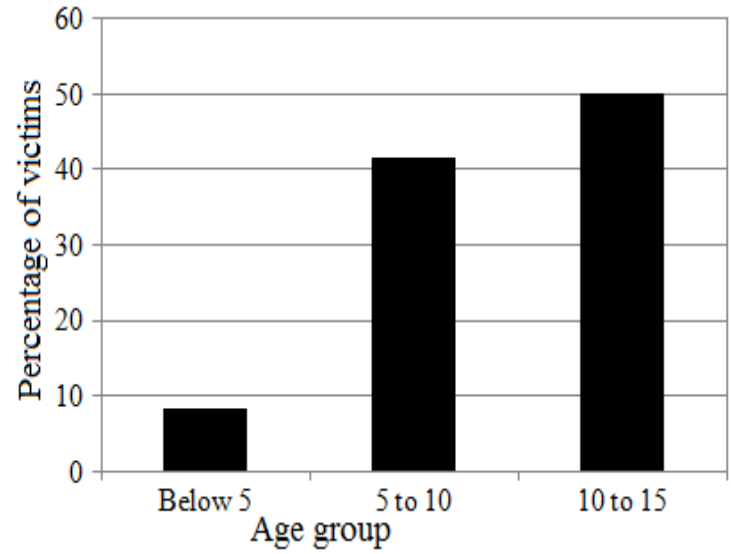

Figure 4. Age group comparison-sleep disorder

\subsection{Hearing Problems}

About $10 \%$ of the children are suffering from hearing problems, of which $58.11 \%$ are boys and $41.89 \%$ are girls. The age wise comparison is as shown in Figure 5. The zone wise comparison shows that $75.73 \%$ are from HEZ and $24.27 \%$ are from RFZ. Here also cell tower exposure is found to be the predominant reason.

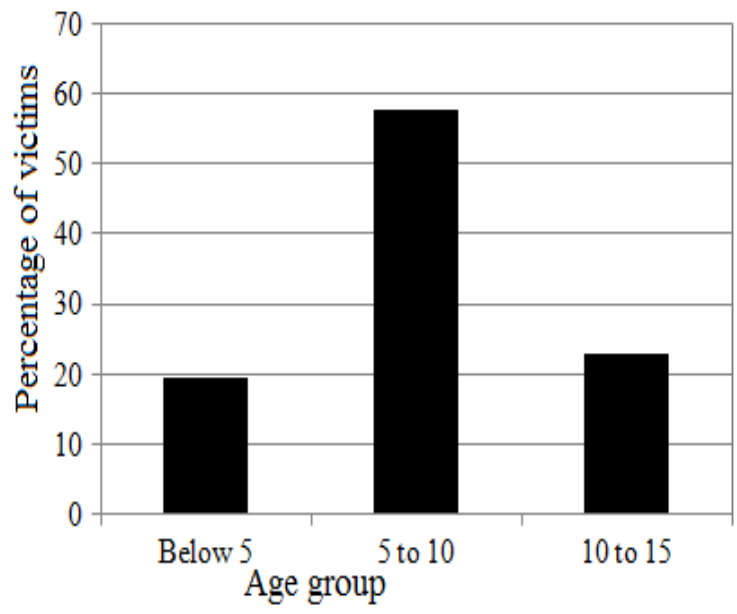

Figure 5. Age group comparison-hearing problems

\subsection{Discussion}

In our work, we measured the intensities of electric, magnetic fields and the power density of electromagnetic field from the residences with the help of MECO's 9720 radiation metre ( 3 axes). Statistical tests (T-test, Levene's Test for Equality of Variances) are conducted to find out the results. The Table 1 explains the mean exposure values concerning the sufferers of the above mentioned diseases and the standard deviations calculated from the tests.

The Table 1 shows that the children stricken by the above diseases are facing higher radiation exposure than the normal one. Standard deviations of E (electric field intensity), H (magnetic field intensity) and $\mathrm{P}$ (power density) regarding the above five diseases are found to be very high. Though the values are well under the ICNIRP and Indian standards, they are found to be very harmful to children under 15 .

Before leaving this discussion, we can recollect some of the key findings of this work. Our study strongly conforms the effect of RF exposure on child health. After the analysis, our ascertainment is that, five diseases have strong connections with cell tower exposure. The diseases are, bone weakness, head aches, rheumatic pain, sleep disorders and hearing problems. The major differentiation of our work when compared with the studies of other researchers is that, we exploited the advantages of the MECO's three axes radiation 
meter. Such a comprehensive study conducted in an eccologicaly sensitive district is for the first time. We have already conducted a general study in Idukki district of Kerala for finding the effects of RF radiations on human [16]. Our current study concentrates on the key findings of that work.

Table 1. Mean Exposure Values and their Corresponding Standard Deviations

\begin{tabular}{ccccccc}
\hline Disease & $\mathrm{E}(\mathrm{mV} / \mathrm{m})$ & Std.Deviation & $\mathrm{H}(\mathrm{A} / \mathrm{m})$ & Std.Deviation & $\mathrm{P}\left(\mathrm{W} / \mathrm{m}^{2}\right)$ & Std.Deviation \\
\hline $\begin{array}{c}\text { Bone } \\
\text { weakness }\end{array}$ & 406.485 & 203.816 & 461.736 & 232.187 & 316.926 & 381.354 \\
$\begin{array}{c}\text { Headaches } \\
\text { Rheumatic }\end{array}$ & 209.219 & 224.211 & 297.309 & 259.227 & 289.989 & 277.866 \\
$\begin{array}{c}\text { pain } \\
\text { Sleep }\end{array}$ & 356.709 & 273.360 & 425.905 & 283.941 & 410.281 & 297.251 \\
$\begin{array}{c}\text { disorders } \\
\text { Hearing } \\
\text { problems }\end{array}$ & 403.422 & 192.370 & 482.480 & 276.207 & 454.386 & 305.603 \\
\hline
\end{tabular}

\section{CONCLUSION}

The effects of RF exposure on the health of children under 15 years had been examined. Five out of the twenty diseases considered are found to be closely related to the RF exposure. The study was carried out in areas at the high ranges of Idukki district which were identified as ecologically sensitive by the Western Ghats Ecology Expert Panel (WGEEP). From our study, it has been found that mobile tower radiation is the primary reason for the five diseases such as bone weakness, headaches, rheumatic pain, sleep disorders and hearing problems found in children. It is also noticed that 10 to 15 age group is more affected. The reason may be long term exposure since all the towers examined were installed at least ten years back. Another inference is that boys are more affected than girls. The reason should be medically examined. The exposure levels are found to be within the limits prescribed by ICNIRP and they conform to Indian Standards. But even then the exposure is found to be hazards to children. So the current exposure standards need to be modified.

\section{ACKNOWLEDGMENT}

Authors are thankful to Dr. Hareesh N. Ramanathan, Professor and head at Toc H Institute of Management Studies, Kochi for his valuable help in conducting the statistical tests. First author is thankful to UGC, Government of India for providing a research fellowship under the FDP scheme.

\section{REFERENCES}

[1] I. Alsaeed et.al. "Autism-relevant social abnormalities in mice exposed perinatally to extremely low frequency electromagnetic fields", Int J Dev Neurosci, vol. 37, pp. 58-64, Oct. 2014.

[2] Y.H. Byun, "Mobile phone use, blood lead levels, and attention deficit hyperactivity symptoms in children: a longitudinal study", PLoS One, vol. 8, pp. 1-10, March 2013. doi:10.1371/ journal.pone.0059742.

[3] G. Coureau, "Mobile phone use and brain tumours in the CERENAT case-control study", Occup Environ Med , vol. 71, pp 514-522, Jul. 2014.

[4] A. Balmori and O. Hallberg, "The Urban Decline of the House Sparrow (Passer domesticus): APossible Link with Electromagnetic Radiation”, Electromagn Biol Med, Vol. 26, pp. 141-151, Feb. 2007.

[5] Md Kamal Hosain, Mst Fateha Samad and Muhammed Samsuddoha Alam, "Effects of electromagnetic fields on mammalian cells", Int J Electric and Comp Eng, vol. 2, no. 2, pp. 267-276, Apr. 2012.

[6] G. Kumar, "Report on cell tower radiation", Electrical Engineering Department, IIT Bombay Tech. Rep., pp. 3-22, Dec. 2010.

[7] Nor Adibah Ibrahim, Tharek Abd. Rahman and Olakunle Elijah, "Recent trend in electromagnetic radiation and compliance assessments for 5G communication", Int J Electric and Comp Eng, vol. 7, no. 2, pp. 912-918, Apr. 2017.

[8] R.S.S.A. Kadir, Zunairah Hj Murat and Nurul Izzati Nadiah Binti Md Suhaimi, "Electromagnetic radiation (EMR) of human body before and after jogging”, Indonesian J Electric Eng and Comp Sci, vol. 9, no. 3, pp. 643-649, Mar. 2018.

[9] A. Jessica Adams et.al, "Effect of mobile telephones on sperm quality: A systematic review and meta-analysis", Environment International, vol. 70, pp. 106-112, Sep. 2014.

[10] C. James Lin and M. Sol Michaelson, Biological Effects and Health Implications of Radiofrequency Radiation, Springer science business media, LLC, 2013.

[11] K.R. Foster, "Thermal and nonthermal mechanisms of interaction of radio-frequency energy with biological systems", IEEE Transactions on Plasma Science, vol. 28, pp. 15-23, Feb. 2000. doi: 10.1109/27.842819 
[12] International Commission on Non-Ionizing Radiation Protection, "ICNIRP Guidelines", http://www.cei.ie/pdf/icnirp guide.pdf

[13] T. Campi, S. Cruciani, V. De Santis and M. Feliziani, "EMF Safety and Thermal Aspects in a Pacemaker Equipped With a Wireless Power Transfer System Working at Low Frequency", IEEE Transactions on Microwave Theory and Techniques, vol. 64, pp. 375-382, Feb. 2016. doi: 10.1109/TMTT.2015.2514087.

[14] R. Bosshard, U. Iruretagoyena and J. W. Kolar, "Comprehensive Evaluation of Rectangular and Double-D Coil Geometry for $50 \mathrm{~kW} / 85 \mathrm{kHz}$ IPT System", IEEE Journal of Emerging and Selected Topics in Power Electronics, vol. 4, pp. 1406-1415, Dec 2016.

[15] Le-Giang Tran, Hyouk-Kyu Cha, Woo-Tae Park, "RF power harvesting: a review on designing methodologies and applications", Micro and Nano Systems Letters, vol. 5: 14, pp. 1-16, Feb. 2017.

[16] P.D. Premlal and N.V. Eldhose, "Mobile tower radiation- an assesment of radiation level and its health implications in the residential areas of Western Ghats in Idukki, Kerala", Int J Applied Eng Res, vol. 12, no. 20, pp. 9548-9554, Nov. 2017.

[17] K.R. Foster and C.K. Chou, "Response to "Children Absorb Higher Doses of Radio Frequency Electromagnetic Radiation From Mobile Phones Than Adults" and "Yes the Children Are More Exposed to Radiofrequency Energy From Mobile Telephones Than Adults"", IEEE Access, vol. 4, pp. 5322-5326, Sep. 2016. doi: 10.1109/ACCESS.2016.2601490.

[18] Mary Redmayne, "International policy and advisory response regarding children's exposure to radio frequency electromagnetic fields (RF-EMF)", Electromagnetic Biology and Medicine. vol. 35, pp 176-185, Feb. 2016.

[19] Report of the Western Ghats Ecology Expert Panel Part I, Submitted to The Ministry of Environment and Forests, Government of India, Aug. 2011. http://www.moef.nic.in/downloads/public-information/wg-23052012.pdf 